DOI:

УДК 621.18:622

С.К. Мещанінов, д.т.н., професор

А.Т. Нельга, старший викладач

Р.В. Волошин, завідувач лабораторії

Д.С. Кривенцов, магістр

Дніпровський державний технічний університет, м. Кам’янське

\title{
АЛГОРИТМ СКОРОЧЕННЯ ТРИВАЛОСТІ ПАУЗИ МІЖ ПРОПУСКАМИ ЗЛИТКУ У ПРОЦЕСІ РЕВЕРСИВНОЇ ПРОКАТКИ
}

Розглянуто алгоритм скорочення тривалості паузи між прокаткою сусідніх розкатів ичклу, який полягає в тому, щзо визначається точка переходу швидкості прокатки на швидкість викиду метала із валків, яка повинна з иього моменту бути зниженою. Для визначення иієї точки переходу враховується маса і довжина частини розкату,що ще знаходиться у робочих валках. Зменшення тривалості середньої паузи в ичилі прокатки не лише підвищує продуктивність, але й істотно впливає на стабільність технологічного процесу прокатки.

Ключові слова: алгоритм; тривалість паузи; темп прокатки; реверсивний стан; прокатні механізми; пропуски.

The algorithm of reduction of duration of pause is considered between rolling of nearby rolls of cycle, which consists in that a transit of speed of rolling point is determined on speed of extras threw from rollers, which from this moment must be less than. For of determination of this transit point mass and length of part of metal of is taken into account, that yet is in the working felling. It is indicated on connection of brief duration of pause with the increase of rate of rolling.

Keywords: algorithm; duration of pause; rate of rolling; reversible figure; rental mechanisms; admissions.

\section{Постановка проблеми}

Збільшення темпу плющення на реверсивних станах є одним з актуальних завдань у прокатному виробництві, що вимагають ефективного рішення. Характерною особливістю реверсивних станів $є$ те, що їх основні механізми, такі як натискний механізм (HM), головний привід (ГП) і робочі рольганги (PР), майже безперервно перебувають у напруженому стані. I від їх узгодженої роботи під час кожної паузи між двома сусідніми пропусками в циклі прокатки, великою мірою залежить величина темпу прокатки [1-2].

\section{Аналіз останніх досліджень і публікацій}

Темп прокатки - параметр, величина якого зворотне величині тривалості прокатки. Середній темп реверсивної прокатки на товстолистових і товсто смугових станах значно занижений і складає $80-87$ \% від максимально можливого. В той же час, зниження цього параметра не лише зменшує продуктивність прокатки, що очевидно, але й впливає на стабільність технологічного процесу [3-5]. Доля його в середніх значеннях дисперсії різнотовщинності готових смуг в партіях доходить до $20-24 \%$.

Як відомо, тривалість паузи, з одного боку, формується викидом розкату із зони деформації у кінці пропуску, а з іншого - реверсом переміщення і захопленням металу робочими валками на черговий пропуск, та перестановкою НМ у нову позицію.

\section{Формулювання мети дослідження}

Стаття спрямована на скорочення тривалості середньої паузи в циклі прокатки, шляхом визначення оптимальної точки переходу зниження швидкості викиду прокату із валків перед черговим пропуском.

\section{Виклад основного матеріалу}

Напрямом підвищення темпу прокатки є розробка відповідних заходів, спрямованих на скорочення пауз, за умови дотримання максимально можливої середньої машинної швидкості прокатки. На підставі аналізу результатів експериментальних досліджень, проведених на стані 
1200 ДМК [1-2] виявлено, що об'єктивною закономірністю зниження темпу прокатки, є нерівномірний характер ведення оператором стану процесу прокатки смугової сталі. Ця нерівномірність проявляється в різних вимогах по дотриманню точності установки або підтримки на заданому рівні режимних параметрів при плющенні від однієї групи пропусків до іншої. Технологічний процес, вже протягом одного циклу прокатки, приймає властивості нестаціонарного, характеризується невизначеністю і обмеженістю вимірювальної інформації, а також багатозначністю варіантів управління, що істотно ускладнює прийняття оператором стану правильних рішень.

Основною складовою збільшення темпу прокатки на реверсивному стані є підвищення середньої швидкості прокатки, яка визначається середньою швидкістю переміщення металу під час його деформації (етап машинної прокатки) і тривалістю пауз між обтисками.

Аналіз результатів досліджень процесу плющення смугової сталі на реверсивному стані 1200, пов'язаних з пошуком резервів підвищення темпу прокатки і їх реалізації, показав наступне. Операторові складно приймати рішення по вибору швидкостей захвату металу валками $\left(V_{\text {заx }}\right)$ і його викиду із зони деформації $\left(V_{\text {вик }}\right)$, що зумовлено існуючими обмеженнями технологічного і технічного характеру. Це найбільш нестабільний етап прокатки в пропуску.

За статистичними оцінками режимів прокатки на реверсивних станах, наприклад, при плющенні смуги завтовшки 10 мм за 15 пропусків із сляба завтовшки 150 мм середня $y_{\text {Vзаx }}= \pm 0,24 \mathrm{~m} / \mathrm{c}$ при $V=0,6 \mathrm{~m} / \mathrm{c}$, а $y_{\text {Vвик }}= \pm 0,45 \mathrm{~m} / \mathrm{c}$ при $V=0,7 \mathrm{~m} / \mathrm{c}$, тобто середньостатистичний розкид значень швидкості захоплення металу складає майже $1 / 3$ частини від статистичного середнього (математичного очікування). В той же час, для середньої швидкості сталого плющення, що складає 2,2 м/с, дисперсія становить $y_{V c m}= \pm 0,15 \mathrm{~m} / \mathrm{c}$.

$V_{\text {вик }}$ вносить істотну долю до тривалості загальної паузи між сусідніми обтисками. Чим

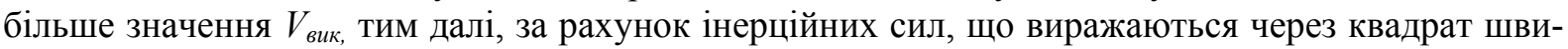
дкості і масу заготівки, буде викинутий метал з валків, а значить, буде витрачено більше часу

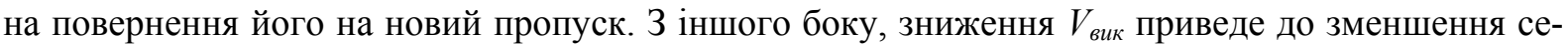

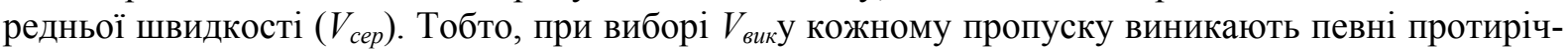
чя, які ускладнюють дії оператора з вибору правильних рішень для отримання максимальної середньої швидкості прокатки і мінімальної тривалості пауз.

Разом $з$ часом, що витрачається на гальмівний шлях розкату $\left(t_{\mathrm{r}}\right)$ при його викиді 3 валків, величина паузи включає і час реверсу $t_{p e s}$ руху розкату і час $t_{p p}$ його доставки робочим рольгангом у зону деформації для прокатки в черговому пропуску.

Окрім перерахованих компонентів, визначуваними режимами роботи головного приводу і приводу рольганга, значною складовою сумарної паузи являється і час переміщення натискного пристрою. Оператор повинен забезпечити необхідне управління головним приводом, приводами натискного механізму і рольгангом 3 таким розрахунком, щоб сумарний час $t_{\Sigma}$, що складається 3 тривалості часу гальмування $t_{2}$ після викиду розкату з робочих валків, реверсу $t_{p e \varepsilon}$ і повернення металу в зону деформації $\left(t_{n}\right)$, був щонайближче до тривалості часу $t_{\text {ни }}$ натискного пристрою (найкраще, коли вони будуть рівні між собою), що витрачається на його переміщення. Дотримання цієї умови, гарантує ритмічність здійснення процесу реверсивної прокатки. При його порушенні, тривалість паузи визначається однією $з$ двох вищезгаданих, сумарного часу $t_{\Sigma}$ або часу переміщення $t_{\text {нм }} 3$ більшою величиною тривалості. Якщо пауза відповідної тривалості визначатиметься сумарним часом $t_{\Sigma}$, машинний час буде зменшеним, порівняно 3 такою ж тривалістю $t_{\mu м}$.

Довжина гальмівного шляху розкату, в основному, визначається швидкістю його викиду з робочих валків. У свою чергу, задана швидкість викиду може бути досягнута правильним вибором моменту (точки) початку рівномірного зниження швидкості прокатки (фаза гальмування), тобто, щоб зниження швидкості прокатки на момент викиду розкату відбувалося до величини, рівної заданої швидкості викиду.

Вказана точка визначається на підставі прогнозу довжини шляху, на яку при плющенні розкат переміститься з цієї точки початку відліку шляху до лінії початку виходу металу з валків. При цьому початкова швидкість зниження $V_{0}$ прокатки дорівнює швидкості сталої прокат- 
ки $V_{c m \cdot n p}$, яка для повної тахограми зміни швидкості переміщення прокату, наприклад,для стана 1200 , відповідає максимально прийнятій $-2,2 \mathrm{~m} / \mathrm{c}$.

Алгоритм визначення мінімальної тривалості циклу прокатки металу зображено на рис. 1. Тривалість пропуску $t$ знаходиться з виразу відношення довжини розкату до швидкості виходу його з валків

$$
t=\frac{L}{V_{\text {вик }}} .
$$

Час паузи між пропусками обчислюють або приймають залежно від тривалості операцій, які здійснюються при подачі розкату у валки, подача по рольгангу, реверс стану, опускання верхнього валка та ін.).

Час прокатки смуги складається 3 машинного часу $t_{M}$ i часу пауз $t_{n p}$.

Загальний час прокатки смуги за $N$ пропусків визначається, як

$$
z_{n p}=t_{0}+\sum_{t=1}^{N} t_{n p}(i)
$$

де $t_{o}$ - тривалість початкової пази, яка визначається в основному часом підйому $\mathrm{HM} ; N-$ загальна кількість пропусків при прокатці смуги; $i$ - поточний пропуск.

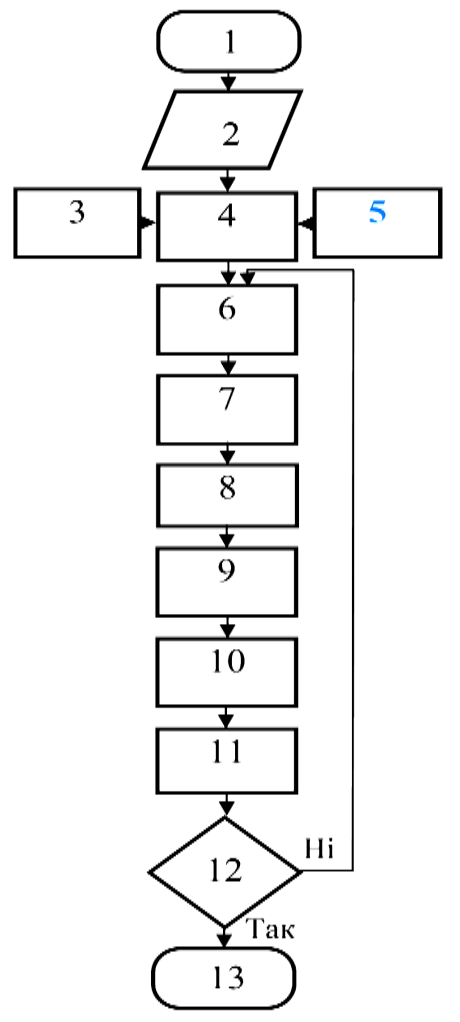

1 - початок прокатки чергового злитку; 2 - ідентифікація етапу в циклі прокатки; 3 -ідентифікація металу, який прокатується; 4 - ідентифікація параметрів злитку й прокатки; 5 - програма обтисків; 6 - розрахунок загальної довжини розкату на поточний пропуск; 7 - розрахунок тривалості часу переміщення НМ на поточний пропуск; 8 - розрахунок оптимальної тривалості паузи в процесі прокатки між сусідніми пропусками; 9 - розрахунок швидкості викиду металу із валків у поточному пропуску; $10-$ розрахунок оптимального вибору точки переходу прокатки у фазу викиду; 11 - уточнення параметрів моделі знаходження оптимальної тривалості паузи; 12 - цикл прокатки завершився. 13 завершення прокатки

Рuc. 1. Алгоритм визначення мінімальної тривалості циклу реверсивної прокатки

Час $t_{n p . i}$ прокатки розкату в одному пропуску:

$$
t_{n p . i}=\sum_{i=1}^{N} t_{\text {M.i }}(i)+\sum_{i=1}^{N} t_{n . i}(i),
$$

де $t_{\text {м.i }}$ - машинний час у $i$-му пропуску; $t_{n . i}$ - тривалість паузи у $i$-му пропуску; машинний час прокатки смуги $t_{m}$ знаходиться:

$$
t_{M}=\sum_{i=1}^{N} t_{M . i}(i)=\sum_{i=1}^{N} t_{M 1}(i)+\sum_{i=1}^{N} t_{M 2 . i}(i)+\sum_{i=1}^{N} t_{M 3 . i}(i)
$$


де $t_{M 1}$ - машинний час при розгоні; $t_{м 2}$ - машинний час при сталій швидкості прокатки; $t_{м 3}$ - машинний час при уповільнені;

$$
\begin{aligned}
& t_{M 1}=t_{M 1}+t_{M 2}+t_{M 3} ; \\
& t_{M 1}=\frac{\bar{\omega}_{2}-\bar{\omega}_{1}}{a_{P}} ; \\
& t_{M 2}=\frac{L_{c}-L_{P}-L_{y}}{V_{P}} ; \\
& t_{M 3}=\frac{\bar{\omega}_{2}-\bar{\omega}_{3}}{a_{y}},
\end{aligned}
$$

де $\varkappa_{1}$ - швидкість обертання двигуна в момент захвату металу; $\varkappa_{2}$ - швидкість обертання двигуна в період постійної швидкості прокатки; $щ_{3}-$ швидкість обертання двигуна в момент виходу металу із валків; $a_{p}$ - середнє прискорення двигуна в період розгону; $a_{y}$ - середнє прискорення двигуна в період уповільнення; $V_{p}$ - швидкість прокатки при сталій прокатці. $L_{c}-$ довжина смуги (розкату) в пропуску; $L_{p}, L_{y}$ — частина довжини розкату, яка прокатана за один пропуск відповідно при розгоні і при уповільнені валків.

$$
\begin{gathered}
L_{p}=L_{y}=V \times t_{M 1}=V_{y} \times t_{1 M 3} ; \\
V_{p . \text {. . }}=V_{y}=\frac{\pi D\left(\omega_{2}+\omega_{1}\right)}{120}=\frac{\pi D\left(\omega_{2}+\omega_{3}\right)}{120},
\end{gathered}
$$

де $D$ - діаметр бочки валків; $V_{p . в}$ - швидкість прокатки при розгоні валків; $V_{y}$ - швидкість прокатки при уповільнені валків.

Тривалість пауз між пропусками визначається за умови

$$
\tau_{n}=\max \left\{t_{H M}+t_{p p}+t_{P B}\right\}
$$

де $t_{H M}$ - тривалість роботи натискного механізму; $t_{P P}$ - тривалість реверсу переміщення розкату; $t_{P B}$ - тривалість реверсу робочих валків; $t_{H M}, t_{P P}$ та $t_{P B}$ знаходяться $з$ виразів:

$$
\begin{aligned}
& t_{H M}=\frac{\Delta h_{i}}{V_{H M}} ; \\
& t_{P P}=t_{B P B}+t_{P 3} ; \\
& t_{P B}=\frac{\omega_{1}}{a_{p}}+\frac{\omega_{3}}{a_{y}},
\end{aligned}
$$

де Дh - абсолютний обтиск у $i$-му пропуску; $t_{B p B}$ - час викиду розкату із валка.

Цей час визначається періодом від моменту викиду до моменту зупинки рольгангу; $t_{P 3}$ - час переміщення розкату до моменту його захвату валками; $V_{B B}$ - швидкість переміщення верхнього валка; $V_{B P}$ - швидкість викиду розкату із кліті; $g$ - прискорення вільного падіння; $f$ - коефіцієнт тертя між металом і роликами рольгангу; $V_{P}$ - швидкість рольгангу.

$$
\begin{aligned}
& t_{B p B}=\frac{V_{B P}}{(g f)} ; \\
& t_{P b}=\frac{V_{B P}^{2}}{\left(2 g f V_{P}\right)} .
\end{aligned}
$$

Ідеальний варіант ритмічної роботи може мати коли співпадають моменти закінчення переміщення ВВ і входження розкату в валки кліті.

При реверсивному режимі захоплення металу валками відбувається при зниженій швидкості, потім швидкість валків підвищується, а перед кінцем пропуску знижується.

Сумарний час, який витрачається на плющення

$$
t_{\Sigma}=t_{\text {aзx }}+t_{\text {ст.мp. }}+t_{p . \phi .} .
$$


В цьому випадку час $t_{c m . n p}$ при максимальній швидкості $V_{c m . n p}$ скорочується раніше, ніж він міг би бути при виборі моменту гальмування більш пізніше. Тому, природно, що загальний час прокатки в цьому пропуску збільшений, хоча тривалість паузи від цієї дії може бути близькою до нуля (час може витрачатися тільки на реверс рольгангів). Проте, для відпрацювання переміщення НМ на черговий пропуск, необхідно ще послідовно витрачати певний час, протягом якого метал знаходитиметься в стані спокою.

Отже, ціною зменшення $V_{c m . n p}$ метал вирушає точніше в позицію, але підстав для скорочення часу плющення в цьому варіанті немає.

Розглянемо числовий приклад по визначенню необхідних параметрів, що зв’язані 3 темпом прокатки. Нехай оптимальне значення швидкості викиду $V_{\text {вик.опm }}=0,4$ м/с. Швидкість сталої прокатки, яка є максимально можливою в циклі прокатки становить $V_{c m . n p}=2 \mathrm{M} / \mathrm{c}$. Переміщення розкату у фазі гальмування приймемо $a=0,5 \mathrm{~m} / \mathrm{c}^{2}$. Тоді тривалість часу, що затрачується 3 моменту початку фази гальмування до моменту викиду:

$$
\tau_{\text {опт. }}=\frac{V_{\text {ст. }}-V_{\text {вик.опт. }}}{a}=\frac{1,6}{0.5}=3,2(\mathrm{c}) .
$$

Довжина розкату, прокатаного в черговому пропуску, що була розрахована у відповідності з величиною обтиску на поточний прохід з урахуванням коефіцієнта подовження складає 18 м. Знайдемо частину довжини розкату $\mathrm{L}_{\mathrm{x}}$, яка була прокатана після початку гальмування при швидкості $V_{\text {вик.опm }}=0,4$ м/с до моменту викиду металу із валків.

$$
\begin{aligned}
& L_{x}=V_{\text {сер. }} \times \tau ; \\
& \tau=\frac{V_{\text {cm. }}+V_{\text {вик. }}}{2}=\frac{2,4}{2}=1,2(\mathrm{c}) ; \\
& L_{x}=1,2 \times 3,2=3,84(\mathrm{M}) .
\end{aligned}
$$

Звідси, перехід у фазу гальмування необхідно здійснювати при плющенні, коли довжина металу $L{ }_{x}{ }_{x}$ буде складати

$$
L_{\text {вик. }}=L_{\text {заг. }}-L_{x}=18-3,84=14,16(\mathrm{M}) .
$$

Інформацію про довжину прокатаної дільниці розкату отримуємо шляхом інтегрування кутової швидкості головного приводу [4-5].

Встановлено емпіричний зв’язок між тривалістю паузи, яка визначається 3 моменту викиду розкату з валків до початку прокатки в черговому пропуску і довжиною переміщення металу під час паузи.

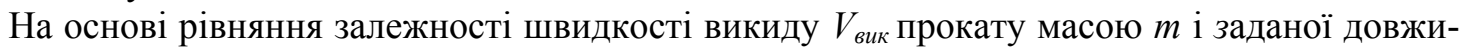

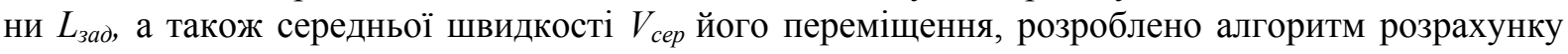
точки переходу прокатки металу у фазу викиду.

Зв'язок між тривалістю переміщення розкату і швидкості викиду встановлено на основі відповідних фізичних закономірностей кінетики переміщення прокату.

Диференціал роботи двигуна головного приводу становить

$$
d A=d\left(\frac{m V_{\mathcal{M}^{2}}}{2}\right)+d\left(F \times L_{A}\right)+d A p,
$$

де $m$ - маса злитку; $V_{M}$ - миттєва швидкість злитку (в початковий момент викиду становить $\left.V_{3}\right) ; F$ - сила опору переміщенню злитку; $L_{A}$ - пройдений розкатом шлях після викиду металу iз валків; $d A_{p}$ - робота двигуна рольгангів.

$$
d A_{0}=d\left(\frac{m \times V p^{2}}{2}\right)+d\left(F \times L_{A}\right),
$$

де $V p$ - швидкість рольгангів.

Залежність $V_{3}$ - швидкості злитку від часу $t$ : 


$$
t=\int_{v_{c}}^{0} \frac{m V_{c} \times d V_{c}}{-F V_{c}} .
$$

Отримане рівняння дає змогу визначити тривалість паузи, що витрачується на переміщення розкату після його викиду із валків.

\section{Висновки}

Наведенні в роботі аналітичні і графічні розв'язання по визначенню темпу прокатки експериментально опробувані та реалізовані на реверсивному стані 1200 і підтвердили зростання темпу прокатки смуг в середньому на $5-7 \%$ в партії $[1-4]$.

Наведений алгоритм може бути використаний для будь-якого реверсивного стан гарячої прокатки. Експериментальні дослідження системи управління процесом точної прокатки смуг на стані 1200 з оптимальною фазою викиду розкатів з робочих валків показали підвищення темпу прокатки в середньому на 5-7 \% в партії, що сприяло зростанню температури в кінці прокатки кожної смуги в середньому на $15-17{ }^{\circ} \mathrm{C}$ і визначило зменшення дисперсії різнотовщинності в партії не менше $2,5 \%$.

\section{Список використаної літератури}

1. Нельга В. Т. Система автоматичного керування процесом точної прокатки смуг / В. Т. Нельга. // Збірник наукових праць ДДТУ, Дніпродзержинськ. - 2009. - С. 37-41.

2. Архангельский В. І. Системы реверсивных электроприводов / В. І. Архангельский. - Киев: Техніка,, 1982. - 387 с.

3. Бойко В. І. Алгоритм определения начала торможения главного привода в текущем пропуске / В. І. Бойко, В. Т. Нельга. // Вісник Криворізського технічного університету. - 2010. № 25 . - C. $214-216$.

4. Никитина Л. А. Черная металлургия, определения торможения главного привода / Л. А. Никитина, Б. Н. Матвеев. // Бюл. АО «Ин-та Черметинформация». - 2003. - № 25. - С.36 - 44.

5. Кравцов А. Ф. Расчет автоматических систем контроля и регулирования металлургических процессов / А. Ф. Кравцов, Е. В. Зайцева, Ю. Н. Чуйко. - Киев: Вища школа, 1981. - 320 с.

6. Глинков, Г. Я. Теоретические основы автоматического управления металлургическими процессами. / Г. Я. Глинков, М. Д. Климовицкий. - Москва: Металлургия, 1985. - 304 с.

7. Васильев В. И. Распознающие системы / В. И. Васильев. - Киев,: Наукова думка, 1983. - 422 с.

8. Губинский В. И. Уменьшение окалинообразования при производстве проката. / В. И. Губинский, А. Н. Минаев, Ю. В. Гончаров. - Киев: Техніка, 1981. - 354 с.

\section{ALGORITHM OF SHORT-TERM PAUSE PROTECTION BETWEEN THE INFLAMMATORY PROCESS IN THE REVIEW PROTECTION PROCESS Meshaninov S.K., Voloshin R.V., Nelga V.T., Krivencov D.S.}

\footnotetext{
Abstract

Increasing the rolling speed at reversible states is one of the most important tasks in the rolling industry, which requires an effective solution. A characteristic feature of the reversible states is that their main mechanisms, such as the push mechanism, the main drive and the working rollers, are almost continuously in a tense state. And from their agreed work during each pause between two adjacent passes in the rolling cycle, the size of the rolling rate depends to a large extent.

The rolling rate is a parameter whose magnitude is inverse in the length of rolling. The average rate of reversal rolling on thick-sheet and thick-banded states is significantly lowered and is 80 $87 \%$ of the maximum possible. At the same time, lowering this parameter not only reduces rolling productivity, which obviously, but also affects the stability of the technological process. The fate of it
} 
in the average values of the dispersion of heterogeneity of finished bands in batches reaches $20-24 \%$.

The article is aimed at reducing the duration of the average pause in the rolling cycle, by determining the optimal transition point to reduce the rate of emission of rolling from the rolls before the next pass.

The direction of increasing the pace of rolling is the development of appropriate measures to reduce pausing, subject to the maximum possible average rolling speed of the machine. Based on the analysis of the results of experimental studies conducted at 1200 Dneprovsky metallurgical combine, it was found that the objective law of decreasing the pace of rolling is uneven the nature of the operator's operation of the process of rolling the strip steel. This unevenness is manifested in various requirements for observing the accuracy of the installation or support at a given level of regime parameters when spinning from one group of spaces to another. The technological process, already during one rolling cycle, accepts the properties of non-stationary, characterized by uncertainty and limited measurement information, as well as the ambiguity of management options, which greatly complicates the acceptance by the operator of the status of correct decisions.

The algorithm presented in this article can be used for any reversible hot rolling state. Experimental studies of the control system of the process of precision rolling of bands at 1200 and with the optimal phase of release of rocks from the working rolls showed an increase in rolling rate by an average of 5-7\% in a batch, which contributed to an increase in temperature at the end of rolling of each band on average by $15-17^{\circ} \mathrm{C}$ and determined the reduction of the dispersion of heterogeneity in the batch at least $2.5 \%$.

\section{References}

[1] Nel'ga A. T. (2009) Sistema avtomatichnogo keruvannja procesom tochnoï prokatki smug [Zbirnik naukovih prac' DDTU]. Dniprodzerzhins'k.

[2] Arhangel'skij V. I. (2008) Sistemy reversivnyh jelektroprivodov Kiev: Tehnika.

[3] Bojko V. I., Nel'ga. A.T (2010) Algoritm opredelenija nachala tormozhenija glavnogo privoda $v$ tekushhem propuske [Visnik Krivorizs'kogo tehnichnogo universitetu]. Krivoyrig.

[4] Nikitina L. A. (2009) Chernaja metallurgija, opredelenija tormozhenija glavnogo privoda Kiev: Tehnika.

[5] Kravcov A. F., Zajceva E. V, Chujko Ju. N. (1981) Raschet avtomaticheskih sistem kontrolja i regulirovanija metallurgicheskih processov. Kiev: Vishha shkola.

[6] Glinkov, G. Ja., Klimovickij M. D. (1985) Teoreticheskie osnovy avtomaticheskogo upravlenija metallurgicheskimi processami. Moskva: Metallurgija.

[7] Vasil'ev V. I. (1983) Raspoznajushhie sistemy. Kiev: Naukova dumka.

[8] Gubinskij V. I., Minaev A. N., Goncharov Ju. V. (1981) Umen'shenie okalinoobrazovanija pri proizvodstve prokata. Kiev: Tehnika. 